\title{
The Northern Territory Intervention in Aboriginal Affairs: Wicked Problem or Wicked Policy?
}

\section{Gary Johns ${ }^{1}$}

This paper takes up the debate kindled by Boyd Hunter in 'Conspicuous Compassion and Wicked Problems' (2007). The present paper's contention is that just as unemployment is a 'matter of choice' - in the words of Treasury Secretary Ted Evans in 1993 - so too is Aboriginal despair. In the case of Aborigines, there is a price to pay for an alleviation of that despair; a change in behaviour. But changing behaviour — in other words, becoming less 'cultural' and less 'authentic' as an Aboriginal - has until recently been ruled out of the policy lexicon. For this reason many Aboriginal people, especially those locked out of the economy and sitting in dysfunctional communities, have paid a price because policy-makers have restricted their choices to a sub-set of those available to other Australians.

The ability of Aborigines to change their behaviour and the cost of change are matters for debate. But as long as appalling behaviour continues, not changing is not an option. At the very least, the recent intervention by the Australian Government into the Northern Territory - the Emergency Response — has opened a space for a more realistic debate about choices in Aboriginal policy.

\section{The origins of wicked Aboriginal policy}

The history of recent Aboriginal policy provides a clue to its ineffectiveness in the face of apparently wicked problems. In doing so it is possible to find that it was the policy-makers' vision that was wicked, not the problem itself.

In 1976 Nugget Coombs, chair of the Council for Aboriginal Affairs, said: 'I wish that some Aboriginal leaders could evolve something equivalent to the Nyerere's [first President of Tanzania] Ujamaa Socialism as a guide and rallying point for their political action' (1976: 15). For the record, Nyerere had tremendous faith in rural African people and their traditional values and customs, and believed that life should be structured around the 'ujamaa', or extended family, found in traditional Africa. He believed that all Africans needed to undo 'imperialism' to return to their traditional mode of life. To that end, Nyerere introduced a policy of collectivisation in Tanzanian agriculture. Unfortunately for Tanzanians, the 'ujamaa system' failed to boost agricultural output. By the

l Senior consultant with ACIL Tasman, and President of the Bennelong Society, G.Johns@aciltasman.com.au. 
time Coombs was waxing lyrical about Nyerere's dream, the collectivisation had ended and Tanzania had gone from the largest exporter of agricultural products in Africa to the largest importer of agricultural products in Africa. Commenting on his economic policies in his farewell speech at his retirement in 1985, Nyerere declared: 'I failed. Let's admit it' (Maier 1998).

Too much faith has been placed in traditional values and ways of life and the attachment to land as both a means of economic and spiritual sustenance. There are few working cattle properties on Aboriginal land anywhere in the north, despite these being in Aboriginal hands since the 1970s: all are leased to white men. Many Aborigines who have claimed Native Title are distraught at the base politicking associated with the claims process, which inflames old family and clan hatreds. Successful claimants do not always visit the land; and if they do, it is often because of the inducement to secure a government job in a cloistered role - for example, as a 'park ranger' or 'environment interpreter'.

In his 1976 address, Coombs (1976: 10) quoted from the 1969 view of anthropologist W. E. H. Stanner (in 'After the Dreaming'): 'When we took what we called land we took what to them [Aborigines] meant hearth, home, the source and focus of life and the everlastingness of spirit.' Clearly, Aborigines have a deep attachment to their land, but it may have been wiser if Coombs had also quoted from the 1958 Stanner (1979: 49):

I have seen a man, revisiting his homeland after an absence, fall on the ground, dig his fingers into the soil, and say: 'oh my country'. But he had been away voluntarily; and he was soon to go away again voluntarily. Country is a high interest with a high value; rich sentiments cluster around it; but there are other interests; all are relative, and any can be displaced.

Land has indeed been displaced as a source of direct sustenance. Sustenance is now indirect - royalties and pensions. Traditional law has been replaced because it does not have an answer for modern problems (such as alcohol abuse) and it cannot provide the remedies for old problems, such as 'improper' marriage, because the discipline required is illegal. The old enforcement kept old men in charge and young men and women in fear of their lives (Tonkinson 1990: 127). There are now far more powerful, fair and malleable sources of law available from the white man.

The recent struggle to save the Aborigine has really been a struggle to save the white man's conception of the Aborigine. It mirrors the earlier misconception in the assimilation period that full-bloods were beyond civilising and half-castes should be separated and intensively schooled. It would be a useful research exercise to see which path - assimilation or self-determination - saved the most lives. The number of people now identifying as Aborigine off-country far 
exceeds those living on-country, and Aborigines who are by and large, integrated into the economy and society are better off on all measures of wellbeing. They have higher incomes, are more likely employed, more highly educated, less prone to diseases, less likely to be gaoled, less likely to be murdered, less likely to contract sexually transmitted infections (Productivity Commission 2007a: Ch. 3; Department of Communities 2006; AIH\&W 2005; Measey et al. 2006; FaCSIA 2007: 56.) and on and on. There are many instances where Aborigines in regional areas and in town camps are not much better off than those in remote areas, and some measures of need (for example, housing) may be the result of inadequate provision; but, as argued below, the investments have been made again and again but have failed to change behaviour for the better.

Indeed, the research agenda in Aboriginal policy has been stunted by wicked policy options. For too long, data on Aboriginal indicators has not been available on a spatial basis; that is, by remoteness classification. For example, children's school attendance has compared Aboriginal with non-Aboriginal and, until recently, it has been difficult to compare the performance of Aborigines in different circumstances. When it has been available, the answers are stark: '[A]verage levels of literacy and numeracy achievement for Indigenous students living in remote areas were substantially below those of other Indigenous students ... In contrast, geographic location had minimal effects ... for non-Indigenous students' (ACER 2005: 3). As the data becomes more readily available, it has become clear that there are three classes of Aborigine: those in discrete communities, mainly in remote areas; those in transition to integration, mainly in country towns; and all others. A new research agenda may be advisable. It should study matters such as integration pathways, Aboriginal migration, and choice-modelling to indicate the cost of individual choices for a given value set, and cost-benefit analysis of all policy options.

\section{The impossible dream created the wicked problem}

Two essential elements of a wicked problem - that the problem is not understood until after a solution has been formulated, and that the stakeholders have radically different world views (see Hunter 2007: 37, quoting Conklin) - apply to Aboriginal policy. Aboriginal policy in the last 30 years has been formulated on the impossible dream that Aborigines could accommodate the new world to suit themselves and that any shortfall in terms of economics or poor behaviour would be picked up or forgiven by the state. The formulation, which may be labelled 'self-determination', has very substantial intellectual support. The alternative position in Aboriginal policy is integration, which is indeed a radically different world view. It suggests that Aborigines are entitled to reach their own accommodation with the modern world but not in a way that requires constant subventions and not in a way that condones bad behaviour. There is an element of pre-judgment in finding the solution to the Aboriginal problem but, as the 
present formulation has been found wanting, it is open to the policy-makers to try. The essential lessons of self-determination are that, in the face of a depleted and non-adaptive culture, group pride is not a good motivator, and attachment to land can be a curse. The alternative is to treat Aborigines as other citizens are treated, and allow them to integrate into the modern economy under the same suite of incentives and disincentives and civil obligations as others. All that remains is for the policy-makers to shift ground.

Hunter's (2007: 37) observation that the 'modernisation project' is inconsistent with the maintenance of 'culture' is a good starting point. Many have observed the ways in which Aboriginal culture is inconsistent with success in a modern economy, but few have been game enough to suggest a path to overcome it. Too frequently 'culture' has been used to veil or excuse bad behaviour. For example, it has been recognised for a long time that Aboriginal economies in remote areas operate by 'demand sharing' or 'humbugging' (that is, where kin demand the immediate use of whatever a person owns), rather than by individual accumulation of physical or financial capital (Martin 1995: 19). Yet there is no suggestion Aborigines should be advised that this is why they are poor, or that this aspect of the culture must change. The inconsistencies between personal obligations in more traditional Aboriginal culture and contractual (and work) obligations in a commercial society are at times profound (Folds 2001: 51); yet there is no suggestion that the culture must change (although Folds, at least explicitly, acknowledges that choosing 'culture' is to choose poverty). Aboriginal associations have to cope with the need for impersonal relations which are at odds with customary obligations yet there is little acceptance (Rowse 2002: 231) that the culture must change.

The uncomfortable fact is that, having recognised for decades the impediment that Aboriginal culture poses to success, policy-makers nevertheless chose cultural observance over success. Such choices ensure that the 'cargo cult' (Lawrence 1964) is alive and well. The consequence is that if people are maladapted to modern society they are, in fact, trapped in a culture of bad behaviour, a 'sick society' (Edgerton 1992) that continues to reproduce its awful daily mores. The truth that confronts those who want to preserve culture is that they have not addressed the 1959 position of Paul Hasluck, the then Minister for Territories:

While it is of course, desirable that Aborigines should retain the best aspects of their own culture, it is important for them to realise that tribal obligations have to be considerably modified to meet the basic requirements of the new way of life. So long as the old tribal obligations are felt in that original form, they will retard the advancement of Aborigines towards assimilation. (Paul Hasluck, 1959) 
Strike out the no-longer-acceptable term 'assimilation' and substitute 'economic integration' in the Minister's statement and the sentiment is the same as that of Hunter above (2007: 37): the 'modernisation project' is inconsistent with the maintenance of 'culture'.

That there are parts, if not a great deal, of Aboriginal culture that retards Aboriginal advancement is well accepted. Unfortunately, 'progressive' Aboriginal politics is built around the enduring assumption that cultural preservation is fundamental to 'identity'. Identity politics works, however, on the assumption that group bravado works better as a motivator than the individual desire to do better (Sowell 2005: 256). For example, despite suffering discrimination, immigrant groups who succeed in the adopted society do not wait for their political leaders to broker a 'solution' on their behalf. Instead, they set out to succeed in the things that are most likely to determine their future, such as the labour market. In addition, although it is possible for a racially distinct middle class to emerge, as among American blacks, the common course is for successful immigrants to succeed through intermarriage as well as economic engagement. While the intermarriage rate for an Aboriginal woman in Sydney is 84 per cent, it is four per cent for an Aboriginal man in the NT outside of Darwin (Birrell 2007). For those in remote areas, the prospects for one form of integration are poor.

The emphasis on sustaining Aboriginal land, culture and language ignores the effect on the inability to produce goods and services that the rest of the society wants. The result has been unhappy and poor people. The 'culture cult' (Sandall 2001) has been a curse in the way that the 'resource curse' and the 'aid curse' (Bhagwati 2005) have. Each has disabled the hopeful beneficiaries of those windfalls and for much the same reasons. Aboriginal aid passed its absorptive capacity a long time ago; the wastage and the damage has been phenomenal.

\section{Two interventions in the Northern Territory}

The two interventions in the Northern Territory - the NT government's Wild and Anderson report, and the Howard government's Emergency Response illustrate vastly different conceptions of, and solutions to, the wicked problem of Aboriginal communities.

The origins of the Australian government's Emergency Response in remote Aboriginal communities seem to be an object of fascination. According to one source, 2 the circumstances were that the April 2007 NT government report on child sexual abuse, Little Children are Sacred (Wild and Anderson 2007), had caught Prime Minister Howard's attention. The result was that the Prime Minister mentioned to his Minister, Mal Brough, shortly before a Monday question time

\footnotetext{
2 As told to the author by Mal Brough, 11 January 2008.
} 
in the House of Representatives that he was thinking of 'cutting off the grog' in Aboriginal communities in the Northern Territory. The matter was raised by Howard in Cabinet the same afternoon, but as a standalone measure Brough was opposed. As a result, Brough was asked to bring a package to Cabinet later that week, and he sat down after Cabinet and wrote at the top of a sheet of paper 'How to fix a town' and proceeded to build a 'to do' list. He took his thoughts to his senior officers and by Thursday's Cabinet meeting the intervention package was born. The intervention took place in June 2007 and the legislation to accompany the intervention was introduced in August 2007.

Clearly, John Howard wished to make some form of dramatic move on Aboriginal communities, and the wish presented the Minister with an opportunity to intervene in a bold manner. He did so with a military model in mind, using logistics-people who could do things on the spot: no meetings, no permits, no obligations and no negotiations - the things that strangle resolve - just doing what he deemed necessary.

The background to the Minister's conception of the intervention was that in May 2006 Nanette Rogers, a Deputy Crown Prosecutor in Alice Springs, had revealed the widespread nature of child sexual abuse in the Northern Territory. Subsequently, Brough secured agreement from a national summit of the states (hastily convened) to work on child sexual abuse. But nothing happened. As is often the case in politics, an old agenda was brought forward at the propitious moment, and the Wild and Anderson report Little Children are Sacred was used as the pretext. While the report was the catalyst for the Howard government intervention, it was never the intention of that government to implement the recommendations of the Little Children are Sacred report. Implementation (another form of intervention) was left to the Northern Territory government.

More recently, the new Labor government has extended to Wadeye in the Northern Territory and the Kimberley in Western Australia the income-management scheme contained in the Emergency Response legislation, and the Noel Pearson-inspired Family Responsibilities Commission will be the vehicle to expand income management to Cape York in Queensland. Labor also wishes to reinstate in a modified form the permit system and has plans to modify, presumably meaning keep alive the Community Development Employment Projects (CDEP) program.

To characterise the respective interventions, the first risks saving the and losing the child (NT government and self-determination) and the second risks saving the child and losing the culture (Howard government and integration). Unfortunately, to lose the child is to also lose the culture. While this characterisation may be too stark and is no doubt oversimplified, the trade-off it implies proves too hard for most governments. They prefer to avoid the trade-off by recommending rounds of consultations and reinventions of existing 
programs. The Wild and Anderson report confirmed the depth of the problem of child sexual abuse in Aboriginal communities in the NT. The recommendations, however, assume that so long as more funds are applied and the community is consulted, life should continue in remote communities ${ }^{3}$ without changes to economic incentives. The Howard intervention on the other hand was preceded by major changes to economic incentives such as the removal of remote-area exemptions for social security obligations, effectively the abolition of Indigenous Community Housing Organisations and encouragement of home ownership, an implied consolidation of communities by withholding funds from homelands and outstations ${ }^{4}$ with the abolition of the Community Housing and Infrastructure Programme and its replacement by the Australian Remote Indigenous Accommodation Programme, the regularisation of training and unemployment incentives with the abolition of CDEP, changes to land tenure though the Aboriginal Land Rights (Northern Territory) Amendment Act 2006, and so on.

The critics of the Howard intervention are concerned that Aboriginal people have been subjected to a great deal of management. It is clear, however, that Aboriginal people are already subject to a great deal of management, either from white public servants or black political leaders. Living collectively means being managed; failing to integrate, and therefore failing to lead an independent life, means being managed. Those whose policy goal is autonomy for Aborigines need to appreciate that autonomy is conditional and mostly available to those who make a contribution to the common wealth. Sitting in a camp, playing cards and neglecting children does not constitute a contribution. The first rounds of mutual obligations in Aboriginal policy were designed to shift behaviour from dependence to autonomy by enforcing obligations on beneficiaries. Unfortunately, they ran into another cultural blocker: they were focused at a collective level. The agreements ran into the sort of problems that all programs for Aboriginal people do; that responsibility is not sheeted home to individuals. Consequently, Shared Responsibility Agreements, which are collective bargains between communities and government for the performance of certain functions in return for infrastructure - for example, 'no school- no pool' - have consumed an enormous amount of public investment with very little return. Nevertheless, the exercise allowed the discussion of obligation to be raised, albeit in ineffectual community forums. The next step is to make obligation an

3 'Community' is here taken to mean a common location where the majority of people are Aboriginal and which has more than 250 people. It is permanently occupied and has a minimum of three services such as a school, clinic and store, and full access to all utilities. It will also have a legal corporate governance and management structure (Phillpot 2007: 3).

4 'Homeland' is here defined as a common location occupied by the traditional owners or those people with a direct link to the traditional owner of the land. It has fewer than three services and may or may not be permanently occupied. 'Outstation' is similarly defined and is distinguished by the fact that the residents may not be able to demonstrate traditional ownership and may only have a general association with the area (Phillpot 2007: 3). 
everyday part of the incentive and compliance structures that every person must face, as for example canvassed by Andrews (2005) in a case study of Mutitjulu in the NT. The Family Responsibilities Commission experiment in Cape York is the next generation of the mutual-obligation experiment. It creates individual incentives and obligations and is built on the observation of Folds (2001: 50, 82) and many others that Aboriginal accountability to kin is far stronger than to community. In other words, Aborigines in remote communities are not overly collective in a western or socialist sense; they are kin oriented.

Policies such as 'work for the dole', lax policing of truancy, poor enforcement of rent payment and, until very recently, remote-area exemptions to social-security obligations, when coupled with living in places with poor work prospects cause bad behaviour. Rather than mask poor policy with massive resources it would be better to change the policies to change behaviour, at the same time anticipating the problems along the way. Government, hopefully in conjunction with Aboriginal people, must set the parameters that allow each person to know what is acceptable and what is not. People should have choice and know the consequences of their actions. In the case of children for example, they should be afforded the right to protection and the obligation of compulsory school attendance. Where such rights and obligations are unachievable, as will be the case in many remote discrete communities, they must be delivered in ways and in places that are achievable. The policy task is to find an exit strategy for Aborigines locked in discrete remote communities, town camps or, indeed, in urban ghettoes. Such paths will not be free of casualties, but the present policy-settings indulge horrendous outcomes.

The casualties of integration will be those people who cannot adjust to modernity. For those who are pessimistic at the prospects for behaviour change, the numbers will be large; for the optimists, the numbers will be small. For example, Folds' (2001: 181) understanding of the Pintupi of the Pilbara is that they 'are an innovative, modern people, engaging selectively and creatively with the contemporary world while living their lives with great exuberance on their settlements'. Folds is clear that in pursuing their lives Pintupi will remain materially poor and dependent. Policy-makers find the trade-off between preserving culture and equality unacceptable, so they fund the culture and the poverty alleviation caused by the culture. Where the 'exuberant' lifestyle, however, descends into child abuse, violence and substance abuse the policy masking becomes unacceptable. This is not to argue that family obligations need to be broken or families broken up in the search for work. It should be possible for more-traditional Aborigines to live closer to work and maintain their ties; but where maintaining their land base and kin ties becomes the sole purpose in life, equality cannot be expected. Where behaviour descends into abuse it cannot be tolerated. 
In fumbling towards the realisation that the previous policy settings did more harm than good, the Howard Government intervention sought to change the long-term policy goal in Aboriginal affairs. It was becoming more acceptable to assert, for example, that being an 'Aborigine' was no longer an excuse for absence from the primary civic obligation of compulsory school attendance. School attendance had been allowed to slide because the outstation or homeland movement of the 1980s removed children from schools. Education departments found supplying teachers to outstations very difficult. In some settlements behaviour was so bad that normal schooling was difficult because the child attending was not prepared in the manner expected and assumed. The child was not well rested, nourished and ready for the day's lessons. Self-determination created a wicked problem for Aborigines. Their lives were confined to the insular world of Aboriginal politics and public-sector provision.

Wild (2007: 119) has been at pains to point out that the Howard government's intervention 'missed the central point' of the recommendations of his report. As noted above, it was never the intention of the Howard intervention to implement the Wild recommendations; but, for the purposes of the debate, Wild argued that no solution should be imposed from above and community involvement was a key component of the solution. Like a score of previous reports on Aboriginal child sexual abuse, the Wild and Anderson report suggested that the root causes were the 'breakdown of Aboriginal culture and society' and that 'community involvement' and/or 'consultation' were an essential response (Wild 2007: 113). The authors of the report were well aware that consultations are the lingua franca of Aboriginal life. At a recent review of the Community Housing and Infrastructure Programme, for example, there were 132 consultation meetings in three months in one community alone (FaCSIA 2007: 14). The fact that consultations were not an aspect of the Emergency Response may be a break with convention, but consultations are no measure of policy effectiveness. Indeed, consultations are an example of a policy goal or, more accurately, a policy-maker's goal that may inhibit a policy solution.

For the most part, the Wild and Anderson recommendations call for more funds to be devoted to public goods and services in Aboriginal communities. There is no mention of the fact that the appalling behaviour which was the subject of the report was probably not exhibited in earlier generations when resources were much less-readily available. The recommendations do not seriously challenge the assumptions of business-as-usual in Aboriginal policy. The report offers a very conservative response to a problem which it, like the Howard government, regards as an emergency. The recommendations proceed on the assumption that Aboriginal 'culture' and 'society' can be fixed, and fixed in a very particular way. That is, even though a large proportion of the population exhibits appalling behaviour such people should be the master of their destiny and stay on their country, regardless of the ramifications for their safety, health, 
education and employment prospects. Changing culture and changing bad behaviour, much less the challenge of modernisation, are not mentioned. By contrast, a member of the Australian government's National Emergency Response Taskforce concluded:

Those people living on remote communities, including those people who have moved there from remote outstations, who are capable of working or training for work and who cannot find a job or job training there, may well have to move closer to the nearest available jobs or job training facilities i.e. the nearest regional towns. (Reeves 2007: 8).

The wicked problem dissolves very quickly when the policy goals change. While there is a price to be paid for each Aboriginal policy path, the price of Aboriginal self-determination is proving very high. Those who would argue that the self-determination revolution is incomplete need to take stock: literally they need to assess who has benefited from the dream and who are the casualties. They may like to test whether the children of assimilation are happier than the children of self-determination. Assimilation was a crude policy designed to create paths for Aborigines into the Australian society. It involved leaving behind all remnants of the earlier identity, although often for good reason (Marchant 2003). This policy was ill-founded because it is now clear that 'identity' is important to wellbeing. But self-determination involved creating an entire life around 'identity'; so much so that it excused and continues to excuse bad behaviour. In the post-self-determination era new paths to integration need to be mapped and the minimum obligations for receipt of the benefits of the society need to be stated.

\section{Misplaced fear of old problems - fringe dwellers}

A reason for wicked policy is that Aboriginal adjustment almost inevitably involves changing locations. There are few jobs in remote locations (DEWR 2006) and if Aborigines are to engage in the workforce they will have to move to those places where jobs exist for their level of skill, which by and large means a shift to town. Encouraging people to stay on their land and outside of the labour market incurs a real penalty. Indeed, having people come to town incurs a real penalty, but the difference is that the former is permanent and the latter may be temporary, provided people change their behaviour along with their location. So long as provision is made to assist people to adapt, the long-held fear that Aborigines are 'coming to town' (see Etherington 2007) is misplaced.

Aboriginal settlement policy is rarely explicitly stated, but the emergency intervention and other housing-policy initiatives of the Howard government provided some indications. There seemed to be a covert policy of physical consolidation of Aboriginal communities because the 73 'intervention' communities were quite simply chosen on the basis of size (any community over 
100); the inference being that the Australian government would no longer service any smaller community. Wadeye in the NT, for example, would be funded not because it deserved the same infrastructure as any town the same size (the public rationale), but because of the fear that if the largest Aboriginal community could not survive then no others would. The entire edifice of discrete Aboriginal communities would collapse.

The settlement side of the intervention (or the assumptions behind it) have not been thought through. It could be concluded that the aim is the consolidation of larger Aboriginal settlements, presumably based on the assumption that these are easier to service. Indeed, outstations are not easy to service but the cost of servicing is a minor matter. The real policy must be to work out how to best place Aborigines in a position to enter the labour market. No matter how inventive public servants are in relabelling employment programs as Aboriginal investment programs, the market will not come to remote communities. If people are to locate near a labour market they will come to town and lest they end up in town camps and recreate the appalling behaviour of outstations then they will have to be managed. The short-term adjustment is akin to a refugee problem. It will be expensive and difficult but it has a realistic outcome. The present policy is to hope or pretend, a la Folds (2001) that there is something innovative going on 'out there'. There is not: the reason for the Emergency Response and the Wild/Anderson Report is that mayhem is going on out there.

Supporters of Aboriginal land rights worry about securing a future for Aboriginal people in a culturally identifiable way, but they share with the white society the worry about fringe dwellers. Such concerns have a long history. A. O. Neville's (the Aboriginal Protector) advice to Rod Schenk (missionary) of Laverton Western Australia is as fresh today as it was in 1920s: 'Don't collect the natives near a town, or they'll become a nuisance, and then we shall have to shift both you and the natives' (Morgan 1986: 1).

And:

It is hard to conceive of anything more unlovely or degraded than the dirty native who hangs around the Australian bush towns, clad in the filthy cast-off garments of bush civilisation, but the same native in his natural state is a very different being.

Right Reverend G. White, Eastern Cape York, 1927 (quoted by Chase 1988: 122).

The observation persists that an Aborigine on his land will be fine, while an Aborigine attempting to integrate to white society living on the fringes is damned. But an Aborigine behaving badly by sitting around playing cards and drinking can occur in remote localities 'on country' and in town camps and in urban ghettoes. Wherever it occurs, such behaviour is unacceptable and there 
are laws in place to penalise and or assist people stuck in such a funk. But there seems to be an assumption that such behaviour is more acceptable for Aborigines on their own land. The probable reason is that they are out of the way. Excusing bad behaviour on Aboriginal land prevents intervention and prevents adjustment. It also provides a ready-made escape from the need to change behaviour.

Some clues to the growth of recent inappropriate policy and the fear of fringe dwellers may be gleaned from the 1982 report of the House of Representatives Standing Committee on Aboriginal Affairs 'Strategies to Help Overcome the Problems of Town Camps'. The report contained a letter from the infamous Robert Bropho, latterly gaoled for indecently dealing with young girls at the Swan Valley Nyungah community (now closed). He stated: 'All Aboriginal people became fringe dwellers the day the white man set foot upon this continent. All Aboriginal people are fringe dwellers until the land is given back' (Standing Committee on Aboriginal Affairs 1982: 3).

The Committee indulged the Bropho view but failed to realise its implications for Aboriginal people. It noted that making town camps more attractive would attract people from outstations. While supporting three strategies - improving town camps, relocating people into conventional housing, and making outstations and properties more attractive - the real emphasis of the recommendations was to increase support for outstations and buttress CDEP (work-for-the-dole) in home communities so as to attract people away from town camps, thus making integration more difficult.

Perhaps as damaging was the acceptance of advice that fringe dwellings should be legitimised by calling them 'town camps'. Fringe dwellings convey a sense of transition; 'town camps' implies permanence. In its settlement manifestation the essence of the apparently wicked problem is that policy-makers have been, and are, prepared to play ping-pong with Aborigines. They hope that the 'culture', which policy-makers know is bad behaviour, can be kept out of sight by keeping Aborigines out of town. But in keeping Aborigines out of town they deny them the chance to gain a foothold in the economy. Treating a very difficult problem as wicked is to duck the responsibility in the hope of avoiding the downside of the only sustainable option: integration including relocation.

The implications for such policy indulgence are profound. For example, a key issue for government is to decide where to build new houses for Aborigines. A view from one Aboriginal leader suggests that houses cannot be built in many existing communities: 'No Government can justify keeping on building houses in the middle of nowhere where there is no school, no healthcare, no law and order, unreliable power and water, no jobs ... and no hope for another generation of our young people' (FaCSIA 2007: xx). 
The fact is that the Australian government has invested around \$2 billion in Aboriginal housing over the last 10 years without an appreciable increase in the number of houses (Brough 2006). In the last five years, the Aboriginal housing stock has only increased by 471 , or 2 per cent, to 21,758 ; and in the Northern Territory there are 271 fewer houses than there were five years ago. In 2005-06 the Federal and State governments spent \$2.4 billion (Productivity Commission 2007b: 228; Australian Government Secretaries' Group) in dedicated housing-and-accommodation support programs for Aborigines. In addition, Aborigines have access on a needs basis to a range of other accommodation support services on the same basis as other Australian citizens (FaCSIA 2006: 101). Shortages are not the result of any underspend. A major cause of the shortage is a lack of care for houses. It stems from a cultural problem - many Aboriginal people do not understand that an asset needs to be maintained. Cooper and Morris (2005: 30) highlight a further aspect of a 'cultural' problem aligned with the abuse problem:

[When] men who perpetrate domestic violence or sexual abuse stay in the houses ... the women and children [are forced] to leave to seek somewhere safe to live: there are men around here living in five bedroom homes by themselves. The women move and the blokes stay in the house.

While 'culture' prevails, it is very difficult for governments to provide adequate housing. Consequently, the existing housing stock has been appallingly maintained. In the last five years, the proportion of the housing stock needing major repairs increased from 19 per cent to 23 per cent (ABS 2007). Aboriginal-controlled/inhabited housing, for example, lasts about seven years while other government housing lasts about 40 years. The problems are exacerbated because very low rents are charged on Aboriginal housing in remote communities and land-tenure limitations prevent people from exercising any option other than to wait for government to build them a house. In some communities the dominant families have houses in their homelands and in the main community. Most homeland people spend much of their time living with relatives in the larger communities where services such as health, education, retail and recreation are livelier. Housing allocation is a constant source of grief for people who continually miss out, particularly those families with many young children who have witnessed for many years the differences in housing renovations, size, siting and number being provided to dominant families.

Typically, policy response to these problems has been to mollify the needs of what has become a recreational lifestyle among remote-area Aborigines. For example, to facilitate visits by kin, the design of new houses in remote centres would 'benefit from well-sized, positioned and perhaps screened verandah spaces, adequately sized living spaces that can be used to accommodate temporary campers, detached shade structures that can accommodate visitors, well designed 
wet areas, additional showers and toilets' (Memmott 2006: 4). And further, 'to provide a base for relatives from outlying communities, new house designs and renovations in the regional centres should be created to accommodate such semi-permanent migration of relatives' (Memmott 2006: 5). The policy suggestions arising from these observations are that Aborigines should have built for them houses sufficient for all of their guests at both ends of their journey, in remote areas and in the regional centres as they circulate between the two. As Folds (2001: 79) makes abundantly clear:

When symbols of social justice, such as houses, are provided there is an anticipation of equal outcomes ... and of grateful Pintupi repaying the government by living in the houses ... what bureaucracy see as a small price to pay for government 'generosity' is actually an extremely difficult and complex expectation to fulfil.

The town camps may be compared with the dark satanic mills of industrial England, but the mill towns were places of transition. People who lived in tenement houses at the turn of the 20th century, for example, did not stay long. They got a foot in the door of the emerging economy through the garment industry and then moved on both geographically, to the suburbs, and economically, to establish new businesses. In short, people adapted. Aborigines may be culturally more removed than Europeans from the 'needs of industry' but the journey is just as vital. Preventing people from adapting is dangerous and harmful. It leads to abuse of alcohol, of wives and children.

\section{Misplaced fear of old problems - economic change}

Aboriginal adjustment also inevitably involves economic change. In this area the fears of policy-makers have tended to vacillate between the insult of being lower class and the distaste for being white. In the mission period, the criticism was that Aborigines were only prepared for modest roles such as labourer or domestic servant. In the self-determination period, the tendency was that Aborigines should not be prepared for anything much except perhaps as elders, artists and representatives. That Aborigines may have to start at the bottom of the pile is no different from any uneducated and poorly assimilated group refugees, for example. The preference that Aborigines should only work in some culturally appropriate tasks, thereby preserving their culture, is debilitating. The policy-maker may have to make a bold assumption, but a modest start in the real economy is better than being held in a designated Aboriginal role for all time.

Various economic policy options have been suggested for Aborigines (for example, Phillpot 2007). Most, however, run into problems (highlighted below in italic) of designated roles. For example: 
- The welfare model - where people are recognised as being outside the mainstream economy and on that basis are supported until such time as they have the desire and the capacity to relocate and participate in the mainstream economic life of the community.

Such desire never arises because the incentives are to remain on welfare. There are significant numbers of African refugees in Darwin who, despite their obvious racial identification and poor skills, are employed. By contrast, many Aborigines are unemployed. The expectation among Aborigines is that they do not have to work, and the welfare model which was supposed to be temporary became permanent when Aborigines were exempted from the obligation to seek work. They were free to pursue land claims, which left them stranded on uneconomic land seeking rent from mining companies, and to practise self-determination, which left them at the mercy of those who controlled the purse strings within their own communities - not to mention an army of 'helpers'. It is wicked policy to make Aboriginal welfare contingent on their preparedness to enter the real economy when the incentives are to penalise entry into the real economy.

- A self-sufficiency substitution model where labour is substituted for capital through 'sweat equity'. Part of this model was a feature of missions and government settlements and elements of this approach underpin such programs as the CDEP. ${ }^{5}$

This option is really an 'import substitution' model and it suffers from the same fate as the welfare model: it becomes a permanent substitute for engaging in the economy, and is not a good bridge to the economy.

- A national-interest transfer model, where representatives of a community or individuals in a community take on contracts to carry out activities that are of regional or national interest. Examples include a national Indigenous land-conservation and management program.

Programs that are really in the national interest, as opposed to those in the interest of those who want to have Aborigines shepherded into a designated band of employment options, should be available to all. It could be argued that employment in the mining or tourism industries is in the national interest, but Aborigines are not employed in large numbers in these industries because they are paid to not work, or are not job-ready.

5 There are good examples of 'sweat equity': Habitat for Humanity builds houses with people who would otherwise be unable to obtain finance. The secret to $\mathrm{HfH}$ is that, in addition to 300 hours of sweat equity, the owner has to pay the mortgage; that is, carry the risk. 
- A population relocation model where continued location in remote localities is made so prohibitive that people in remote communities have no other option but to relocate to regional localities where there are services and employment.

The population relocation model is a misnomer because it is not a compulsion to relocate. The model is also stated somewhat pejoratively because continued location is not made prohibitive, it is prohibitive. It is clear that in addition to the prohibitive social and economic cost of preserving non-viable communities, people are moving away to seek opportunity. The risk of this model is that people will move to such centres without the skills, knowledge or social capacity to operate independently and, as a consequence, will create underclass communities in regional centres whose various needs and behaviour are beyond the resources of the regional centre to cope.

The big risk to people sitting in remote communities, even while being prepared for integration, is that the total environment - social and economic - is just too dysfunctional. The two great mechanisms of integration migration and intermarriage - are unlikely while the policy biases are towards land-based and culturally collective 'solutions'.

\section{Who better understands Aboriginal culture?}

The great contradiction of Aboriginal policy of the last 30 years is that the assimilationists better understood both Aboriginal culture and its faults and the impossibility of its preservation than those who uncritically sought to preserve it. The latter idealised culture and hoped that it could survive when its economic base was long gone and the very basis of the culture was no longer useful to sustain Aborigines in their new economy. While there were problems associated with the assimilation period, many were transient. Instead, the problems were mistakenly judged permanent. The permanent problems arose when programs were devised to stop the integration of Aborigines into the modern economy.

As Pastor Paul Albrecht, lately of the Finke River mission at Hermannsburg and a critic of the assimilation policy, has remarked:

There is nothing sacrosanct about cultures, and the Aboriginal culture is no exception ... the rationale for taking seriously those aspects of Aboriginal culture still shaping the lives of the more traditional Aborigines is not to preserve the culture, but to utilise the culture to assist Aborigines adjust to the current social and economic situation (Albrecht 2008: 89).

A practical application of Albrecht's observation is the successful Aboriginal secondary school at Djarragun College in Gordonvale, in far-north Queensland. When faced with unruly students, the principal understood the necessity to be utilitarian about Aboriginal (and Islander) culture. She recounted: 
[The students'] joy and energy needed to be nurtured and celebrated and so we dreamed up every excuse for days of celebration and feasting. Cultural performances became a feature of all these celebrations and relatives became involved in teaching students their traditional dances and music. As students' self-esteem and belief in themselves grew, so the behaviour across the school improved. As behaviour improved, so we introduced a more rigorous curriculum and gradually minimised the amount of days of celebration. We got down to two days of celebration a term which allowed us to really spend quality time on delivering accredited courses and to follow the Queensland syllabus (Illingworth 2007: 3).

Therein lies the solution to the wicked problem. If the problem arises because the policy-maker or some clients have impossible or misconceived demands, there is indeed a problem. But if the problem is differently conceived - that is, that Aborigines must learn to adapt to their new environment - it will resolve itself more quickly and with less pain. The idealists may suggest the solution is tantamount to killing the patient, but is the patient an idealised Aborigine or a person? It is possible that policy-makers enjoy the complexity of the multi-faceted

problem. It is rather deflating to be told that it really is straightforward in conception, if not resolution.

\section{References}

Albrecht, P. G. E. 2008, Relhiperra: About Aborigines, Published by the Bennelong Society, http://www.bennelong.com.au/books/pdf/Relhiperra.pdf

Andrews, G. 2005, Economic Passivity and Dependency in Mutitjulu: Some Suggestions for Change, http://www.bennelong.com.au/articles/pdf/gandrews2006.pdf

Australian Bureau of Statistics 2007, Community Housing and Infrastructure Needs Survey (2001-06).

Australian Council for Educational Research, 2005, 'Education and Labour Market Outcomes for Indigenous Young People', Longitudinal Surveys of Australian Youth Briefing 10.

Australian Government, Secretaries' Group on Indigenous Affairs 2006, Annual Report 2005-06.

Australian Institute of Health and Welfare 2005, 'The Health and Welfare of Australia's Aboriginal and Torres Strait Islander Peoples', ABS Cat. no. 4704.0, AIHW Cat. no. IHW 14, Canberra.

Bhagwati, J. 2005, 'A Chance to Lift the "Aid Curse"', The Wall Street Journal, March 22. 
Birrell, B. 2007, 'Consideration of intermix: results and implications from the 2006 Census', paper presented to the Bennelong Society Conference, Melbourne. http://www.bennelong.com.au/conferences/conference2007/conference2007.php

Brough, Hon. Mal MP, Minister for Families, Community Services and Indigenous Affairs 2006, 'Blueprint for Action in Indigenous Affairs', 05/12/2006, Canberra.

Chase, A. K. 1988, 'Lazarus at Australia's Gateway: The Christian Mission Enterprise in Eastern Cape York Peninsula' in Swain, T. and Rose D. B. (eds), Aboriginal Australians and Christian Missions, The Australian Association for the Study of Religions, South Australia.

Coombs, H. C. 1976, Aboriginal Australia 1967-1976: A Decade of Progress?, Murdoch University, Perth.

Cooper, L. and Morris, M. 2005, ‘How to Help Indigenous Families into Stable Housing and Sustainable Tenancy', Australian Housing and Urban Research Institute, Research and Policy Bulletin 56: May 2005.

Department of Communities 2006, Queensland Health Notifiable Disease Register 2005 (unpublished).

Department of Employment and Workplace Relations 2006, 'Audit of Employment Opportunities in Remote Communities in the Northern Territory', with the Local Government Association of the Northern Territory.

Department of Families, Community Services and Indigenous Affairs 2006, 'Housing Assistance Act 1996 Annual Report 2004-05'.

Department of Families, Community Services and Indigenous Affairs 2007, Indigenous Housing: Findings of the Review of the Community Housing and Infrastructure Programme, PriceWaterhouseCoopers.

Edgerton, R. B. 1992, Sick Societies: Challenging the Myth of Primitive Harmony, Free Press, New York.

Etherington, S. 2007, 'Coming Ready or Not! Aborigines are Heading for Town', Occasional Papers Bennelong Society, October 2007, at: http://www.bennelong.com.au/occasional/etherington2007.pdf

Folds, R. 2001, Crossed Purposes: the Pintupi and Australia's Indigenous Policy, UNSW, Sydney.

Hunter, B. 2007, 'Conspicuous Compassion and Wicked Problems', AGENDA 14(3): 35-51.

Illingworth, J. 2007, 'The Journey from Anger to Joy: the Djarragun Story', paper presented to the Bennelong Society Conference, Melbourne. http://www.bennelong.com.au/conferences/pdf/Illingworth2007.pdf 
Lawrence, P. 1964, Road Bilong Cargo, Manchester University Press, Manchester.

Maier, K. 1998, 'Into the House of the Ancestors', extract in The New York Times, February 1, 1998.

Marchant, L. R. 2003, 'From the Diary of a Protector of Aborigines', Quadrant, April: $32-4$.

Martin, D. 1995, 'Money, Business and Culture: Issues for Aboriginal Economic Policy', CAEPR Discussion Paper 101, Centre for Aboriginal Economic Policy Research, ANU, Canberra.

Measey, M. L., Li, S. Q., Parker, R. and Wang, Z. 2006, 'Suicide in the Northern Territory, 1981-2002', Medical Journal of Australia 185(6): 315-9.

Memmott, P. et al. 2006, 'Mobility of Aboriginal People in Rural and Remote Australia', Australian Housing and Urban Research Institute, Research and Policy Bulletin 69, May.

Minister for Territories 1959, 'Fringe Dwellers. National Aborigines Day in Australia', Commonwealth of Australia, 10 July.

Morgan, M. 1986, A Drop in the Bucket: The Mount Margaret Story, Mission Publications of Australia, Lawson.

Phillpot, S. 2007, 'The Future Of Remote Aboriginal Communities: A Series Of Relic Settlements Of People Created By The Ebb And Flow Of Contact With Non Aboriginals', Bennelong Conference 2007: http://www.bennelong.com.au/

Productivity Commission 2007a, Overcoming Indigenous Disadvantage: Key Indicators 2007.

Productivity Commission 2007b, Report on Government Services 2007 — Indigenous Compendium.

Rowse, T. 2002, Indigenous Futures: Choice and Development for Aboriginal and Islander Australia, UNSW Press.

Reeves, J. 2007, 'A personal report from the field', paper presented to the Bennelong Society Conference 2007: http://www.bennelong.com.au/conferences/pdf/Reevespaper2007.pdf

Sandall, R. 2001, The Culture Cult: Designer Tribalism and Other Essays, Westview Press, Boulder.

Sanders, W. 2005, 'Housing Tenure and Indigenous Australians in Remote and Settled Areas', CAEPR Discussion Paper No. 275/2005, Centre for Aboriginal Economic Policy Research, ANU, Canberra.

Sowell, T. 2005, Black Rednecks and White Liberals, Encounter Books, San Francisco. 
Standing Committee on Aboriginal Affairs 1982, Strategies to Help Overcome the Problems of Aboriginal Town Camps, Parliament of the Commonwealth of Australia.

Stanner, W. E. H. 1979, Whiteman Got No Dreaming: Essays 1938-1973, ANU Press, Canberra.

Tonkinson, R. 1990, 'The Changing Status of Aboriginal Women: Free Agents at Jigalong' in Tonkinson, R. and Howard M. (eds), Going It Alone: Prospects for Aboriginal Autonomy, Aboriginal Studies Press, Canberra.

Wild, R. 2007, 'Unforeseen Circumstances' in Altman, J. and Hinkson, M. (eds), Coercive Reconciliation, Carlton: Arena.

Wild, R. and Anderson, P. 2007, 'Little Children are Sacred, Ampe Akelyernemane Meke Merkale, Report of the Northern Territory Board of Inquiry into the Protection of Aboriginal Children from Sexual Abuse', Report to the Northern Territory Government, Darwin. 